\title{
The Thought-Action Fusion scale: Further evidence for its reliability and validity
}

Citation for published version (APA):

Rassin, E. G. C., Merckelbach, H. L. G. J., Muris, P. E. H. M., \& Schmidt, H. G. (2001). The ThoughtAction Fusion scale: Further evidence for its reliability and validity. Behaviour Research and Therapy, 39, 537-544. https://doi.org/10.1016/S0005-7967(00)00031-0

Document status and date:

Published: 01/01/2001

DOI:

10.1016/S0005-7967(00)00031-0

Document Version:

Publisher's PDF, also known as Version of record

\section{Please check the document version of this publication:}

- A submitted manuscript is the version of the article upon submission and before peer-review. There can be important differences between the submitted version and the official published version of record.

People interested in the research are advised to contact the author for the final version of the publication, or visit the DOI to the publisher's website.

- The final author version and the galley proof are versions of the publication after peer review.

- The final published version features the final layout of the paper including the volume, issue and page numbers.

Link to publication

\footnotetext{
General rights rights.

- You may freely distribute the URL identifying the publication in the public portal. please follow below link for the End User Agreement:

www.umlib.nl/taverne-license

Take down policy

If you believe that this document breaches copyright please contact us at:

repository@maastrichtuniversity.nl

providing details and we will investigate your claim.
}

Copyright and moral rights for the publications made accessible in the public portal are retained by the authors and/or other copyright owners and it is a condition of accessing publications that users recognise and abide by the legal requirements associated with these

- Users may download and print one copy of any publication from the public portal for the purpose of private study or research.

- You may not further distribute the material or use it for any profit-making activity or commercial gain

If the publication is distributed under the terms of Article $25 \mathrm{fa}$ of the Dutch Copyright Act, indicated by the "Taverne" license above, 


\title{
BEHAVIOUR
}

\section{The thought-action fusion scale: further evidence for its reliability and validity}

\author{
Eric Rassin *, Harald Merckelbach, Peter Muris, Henk Schmidt \\ Department of Psychology, Maastricht University, PO Box 616, 6200 MD, Maastricht, The Netherlands
}

Accepted 7 February 2000

\begin{abstract}
Thought-action fusion (TAF) refers to a set of cognitive biases that are thought to play a role in the development of obsessional phenomena. To measure these biases, R. Shafran, D. S. Thordarson, and S. Rachman (1996; Journal of Anxiety Disorders, 10, 379-391) developed the TAF-scale. They concluded that the TAF-scale possesses adequate psychometric qualities. The current study sought to further explore the reliability and validity of the TAF-scale. Results indicate that the TAF-scale has good internal consistency. TAF-scores correlated with self-reports of obsessional problems. Furthermore, mean scores in a mixed sample of anxiety disordered patients were higher than those in a normal sample. However, temporal consistency was somewhat disappointing. Also, the question remains whether TAF is specific to obsessivecompulsive disorder or taps more pervasive biases that play a role in a variety of disorders. (C) 2001 Elsevier Science Ltd. All rights reserved.
\end{abstract}

Keywords: Cognitive bias; Obsessive-compulsive disorder; Thought-action fusion

\section{Introduction}

Thought-action fusion (TAF) refers to a set of cognitive biases that are thought to play a role in the development of obsessive-compulsive problems (see Rachman, 1997, 1998). More specifically, TAF consists of two related biases. The first is the probability or likelihood bias, that is the belief that merely thinking of a hypothetical situation (e.g., a car accident) promotes the likelihood that this situation will actually occur. The second is the morality bias, that is the belief that thoughts (e.g., violent fantasies) are morally equivalent to overt behaviours (e.g., violence). Both TAF-biases are believed to increase distress and the urge to neutralise in case of

\footnotetext{
* Corresponding author.

E-mail address: e.rassin@psychology.unimaas.nl (E. Rassin).
} 
unwanted intrusions (Rachman, 1998; Shafran, Thordarson \& Rachman, 1996). While there are more cognitive biases with potential distressing qualities (e.g., the belief that people can and should exert complete control over their thoughts), TAF biases appear to be especially relevant for our understanding of the aetiology of obsessive-compulsive symptoms (Emmelkamp \& Aardema, 1999; Rachman, Thordarson, Shafran \& Woody, 1995).

There is indeed some experimental evidence for the psychopathological potential of TAF-biases. Rassin, Merckelbach, Muris and Spaan (1999) found that successful induction of a TAF-bias in non-clinical participants resulted in a changed evaluation of a neutral target thought. These authors told participants in the experimental condition that any thoughts of the word 'apple' might result in the administration of an electrical shock to another participant. Experimental participants were connected to a bogus EEG that was introduced to them as an apparatus that could pick up their thoughts. After having spent $15 \mathrm{~min}$ in the lab, several visual analogue scales (VASs) were completed. Results indicated that experimental participants experienced more thoughts about apples, and, at the same time, reported more discomfort, and a stronger urge to resist the target thought than did controls. This demonstrates that a neutral thought may acquire obsessional qualities when participants are led to believe that their thoughts have direct, external consequences (i.e., shocks). Similarly, Rachman, Shafran, Mitchell, Trant and Teachman (1996) recruited participants with a TAF-bias. Instatement of an intrusion (i.e., completing a written sentence describing the wish that a person close to the participant would soon be involved in a car accident) resulted in distress, feelings of responsibility and guilt, and a strong urge to engage in neutralising compulsions (e.g., praying). In sum, these studies suggest that TAF-biases may enhance the obsession-like character of intrusions and consequently may provoke urges to engage in neutralising compulsions.

To measure the two types of TAF-bias, Shafran et al. (1996) introduced the TAF-scale. This self-report scale consists of seven items tapping the probability bias and 12 items tapping the morality bias. Their studies indicated that the TAF-scale possesses adequate psychometric qualities. That is, internal consistency proved to be satisfactory $(\alpha \mathrm{s}>0.85)$, and respondents who scored clinically high on a measure of obsessive-compulsive symptoms also had higher TAFscores than normal controls. As well, TAF-scores in both a clinical and a non-clinical sample correlated with measures of obsessional problems and depressive symptoms. Shafran et al. (1996) concluded that "TAF is a highly reliable construct" (p. 387).

The current study aimed at gathering additional information about the reliability and validity of the TAF-scale. Apart from the psychometrics that were previously reported by Shafran et al. (1996; i.e., factor structure, internal consistency, and correlations with self-reports of obsessional problems and depression), we investigated its temporal stability and its association with a measure of fantasy proneness. The latter concept refers to the tendency to become absorbed by daydreaming and imaginations (Wilson \& Barber, 1978). Fantasy prone individuals often have great difficulty in differentiating between actual events and imaginary events. Accordingly, it would be informative to study the connection between fantasy proneness and TAF. Finally, in order to further investigate the discriminant validity of the TAF-scale, TAF-scores of OCD patients were compared to those of patients with other anxiety disorders and normal controls. 


\section{Method}

Undergraduate students $(N=285 ; 227$ women; mean age $=18.9$ years, $\mathrm{SD}=1.5$, range: $17-28)$ completed the Dutch version of the TAF-scale along with several other questionnaires. The TAFscale consists of 19 items that are answered on a 5-point scale ( $0=$ disagree strongly; $4=$ agree strongly). Twelve items tap the morality bias (e.g., "If I wish harm on someone, it is almost as bad as doing harm"), while seven items address the probability bias (e.g., "If I think of a relative/friend losing their job, this increases the risk that they will lose their job"). Of the seven probability-items, three have to do with negative consequences for oneself (i.e., "probability self"; e.g., "If I think of myself falling ill, this increases the risk that I will fall ill"), while four items refer to negative consequences for others (i.e., "probability others"). This distinction is of interest because whereas there may be a rational basis for the probability self construct (in that a belief may actually lead to behavioural change), the probability others construct lacks such rationality. Results of the Shafran et al. (1996) study indicate, however, that especially in a clinical sample, discrimination between these two versions of the probability bias hardly increases the variance accounted for in factor analysis. These authors conclude: "obsessionals may be considered to be engaging in a second 'fusion', that is, the fusion of TAF-likelihood-for-self and TAF-likelihoodfor-others" (p. 387). TAF-total scores range from 0 to 76 with higher scores indicating stronger cognitive biases.

The Maudsley obsessive-compulsive inventory (MOCI; Hodgson \& Rachman, 1977) consists of 30 truelfalse items addressing various symptoms, namely checking (e.g., "My major problem is repeated checking"), cleaning (e.g., "I take rather a long time to complete my washing in the morning"), doubting (e.g., "I am more concerned than most people about honesty"), and slowness (e.g., "I am often late because I can't seem to get through everything on time"). MOCI-scores range from 0 to 30 with higher scores indicating more obsessive-compulsive symptoms.

The revised Padua inventory (PI-revised; Van Oppen, Hoekstra \& Emmelkamp, 1995; see also Sanavio, 1988) is a second measure of obsessional problems. The PI-revised contains 41 items that are answered on a 5-point scale ( $0=$ not at all; 4=very much). Like the MOCI, the PI-revised taps various obsessive-compulsive symptoms such as checking (e.g., "I tend to keep on checking things more often than necessary"), impulses (e.g., "When I see a train approaching I sometimes think I could throw myself under its wheels"), precision (e.g., "I sometimes start counting objects for no reason"), rumination (e.g., "I find it difficult to take decisions, even about unimportant matters"), and washing (e.g., "I feel my hands are dirty when I touch money"). Total Paduascores range from 0 to 164 with higher scores indicating more obsessional problems. It has been argued that the structure of the PI corresponds to a large extent with the different types of phenomena seen in OCD (Van Oppen et al., 1995). Therefore, PI-scores are expected to range broadly, making this scale very suitable for correlational analyses.

The Beck depression inventory (BDI; Beck, 1967) is a widely used 21-items instrument tapping various depressive symptoms (e.g., sadness, irritation, crying). BDI-items are scored on a 4-point scale ( $0=$ not at all; $3=$ very much). Thus, higher total scores (range: $0-63$ ) indicate higher levels of depression.

The Creative experiences questionnaire (CEQ; Merckelbach, Muris, Schmidt, Rassin \& Horselenberg, 1998) is a self-report measure of fantasy-proneness. The CEQ consists of 25 true/false 
items (e.g., "I often confuse fantasies with real memories"). Total CEQ-scores range from 0 to 25, with higher scores indicating stronger fantasy-proneness.

Of the 285 undergraduate participants who completed these questionnaires, 98 filled in the TAF-scale a second time after a 3-months interval in order to establish its test-retest stability. The TAF-scale was furthermore completed by a clinical sample $(N=71 ; 47$ women; mean age $=33.9$ years, $\mathrm{SD}=10.3$; range: 18-72) consisting of 30 obsessive-compulsive disorder (OCD; American Psychiatric Association, 1994) patients and 41 patients with other anxiety disorders (mainly panic disorder, social phobia, and post traumatic stress disorder). Also, 20 non-student healthy controls (14 women; mean age $=39.2$ years, $\mathrm{SD}=14.0$; range: $21-64$ ) completed the TAF-scale.

\section{Results}

\subsection{Factor structure}

Factor analysis with direct oblimin transformation was performed on the TAF-scores of the undergraduates $(N=285)$. Two and three-factor solutions accounted for 49 and $56 \%$ of the variance, respectively. The two-factor solution clearly reproduced the probability and morality subscales, with items exclusively loading on one or the other factor (all loadings were $>0.40$ ). Probability and morality scales correlated moderately with each other $(r=0.32, p<0.01)$. The three-factor solution reproduced the morality subscale and the two types of probability bias (one involving negative consequences for oneself and the other involving negative consequences for others). With this solution, one item loaded on both probability biases. The correlation between probability self and probability others was $0.47(p<0.001)$.

\subsection{Alphas}

Table 1 summarises means and alphas for the TAF-scale, MOCI, PI, BDI, and CEQ. As can be seen, alphas for the TAF-total scores and subscales were satisfactory (all $\alpha \mathrm{s}>0.75$ ).

\subsection{Temporal stability}

Three months retest correlations for the TAF-total $(r=0.52)$, probability $(r=0.51)$, probability self $(r=0.53)$, probability others $(r=0.47)$, and morality $(r=0.54)$ scores were all significant at the 0.01 level. However, mean TAF-scores during the second test occasion were significantly lower than those during the first occasion. More specifically, mean total scores dropped from 20.39 to $16.41(\mathrm{SD}=10.63$ : $t[97]=6.05, p<0.001)$, probability scores decreased from 6.25 to 4.71 $(\mathrm{SD}=4.56: t[97]=5.40, p<0.001)$, probability self scores dropped from 4.16 to 2.77 ( $\mathrm{SD}=2.63$ : $t[97]=6.96, p<0.001)$, while probability others scores decreased from 2.10 to 2.00 ( $\mathrm{SD}=2.60$ : $t[97]=2.03, p<0.05)$, and morality scores dropped from 14.21 to $11.62(\mathrm{SD}=7.96: t[97]=4.95$, $p<0.001)$. Intraclass correlations for the TAF-total, probability, probability self, probability others, and morality scores were $0.68,0.67,0.69,0.64$, and 0.70 , respectively. 
Table 1

Mean scores (standard deviations are given between parentheses) and alphas for the TAF-scale, MOCI, PI, BDI, and CEQ $(N=285)^{\mathrm{a}}$

\begin{tabular}{lcc}
\hline & Means (SD) & Alphas \\
\hline TAF-total & $20.39(10.53)$ & 0.88 \\
TAF-probability & $6.25(4.55)$ & 0.83 \\
TAF-probability self & $4.16(2.80)$ & 0.75 \\
TAF-probability others & $2.10(2.50)$ & 0.89 \\
TAF-morality & $14.21(8.06)$ & 0.89 \\
MOCI-total & $6.7(4.74)$ & 0.76 \\
MOCI- checking & $1.85(1.75)$ & 0.62 \\
MOCI-cleaning & $1.83(1.66)$ & 0.42 \\
MOCI-doubting & $1.72(1.53)$ & 0.55 \\
MOCI-slowness & $1.35(1.50)$ & 0.47 \\
PI-total & $29.35(15.58)$ & 0.91 \\
PI-checking & $5.94(4.71)$ & 0.85 \\
PI-impulses & $3.80(3.67)$ & 0.77 \\
PI-precision & $2.59(2.86)$ & 0.66 \\
PI-rumination & $12.71(5.87)$ & 0.82 \\
PI-washing & $4.49(4.31)$ & 0.81 \\
BDI & $6.19(5.39)$ & 0.79 \\
CEQ & $8.37(4.21)$ & 0.73 \\
\hline
\end{tabular}

a Note: TAF-scale=thought-action fusion scale, MOCI=Maudsley obsessive-compulsive inventory, PI=Padua inventory-revised, $\mathrm{BDI}=\mathrm{Beck}$ depression inventory, $\mathrm{CEQ}=$ creative experiences questionnaire.

\subsection{Construct validity}

Correlations with the MOCI and PI-revised are given in Table 2. As can be seen, there were significant, though modest correlations in the expected direction between TAF-total scores and the two measures of obsessional problems (i.e., MOCI and PI). While TAF-total scores were not associated with self-reports of depression (BDI) or fantasy proneness (CEQ), TAF-probability scales did correlate with BDI and CEQ. But again, the correlations were modest. By and large, the most correlations between TAF-probability scales and obsessional symptoms remained significant when the influence of BDI and CEQ was partialled out.

To compare TAF-scores of students, normal controls, OCD patients, and patients with other anxiety disorders, one-way analyses of variance (ANOVAs) were carried out. Results from these analyses are presented in Table 3. This table shows that students and normal controls scored lower than both clinical samples. Meanwhile, there were no differences between OCD patients and patients suffering from other anxiety disorders.

\section{Discussion}

The present results can be summarised as follows. To begin with, thought-action fusion as indexed by the TAF-scale seems to consist of two separate but modestly correlated factors, with 
Table 2

Correlations between the TAF-scale and the MOCI, PI, BDI, and CEQ $(N=285)^{\mathrm{a}}$

\begin{tabular}{llllll}
\hline & TAF-total & TAF-probability & Probability self & Probability others & $\begin{array}{l}\text { TAF- } \\
\text { morality }\end{array}$ \\
\hline MOCI-total & $0.21^{* *}$ & $0.23^{* *}$ & $0.23^{* *}$ & $0.16^{*}$ & 0.13 \\
MOCI-checking & $0.16^{*}$ & $0.18^{*}$ & $0.17^{*}$ & 0.14 & 0.11 \\
MOCI-cleaning & 0.15 & $0.22^{* *}$ & $0.20^{* *}$ & 0.17 & 0.07 \\
MOCI-doubting & $0.21^{* *}$ & 0.12 & $0.17^{*}$ & 0.03 & $0.20^{*}$ \\
MOCI-slowness & 0.10 & 0.15 & 0.14 & 0.12 & 0.05 \\
PI-total & $0.32^{* *}$ & $0.29^{* *}$ & $0.26^{* *}$ & $0.27^{* *}$ & $0.27^{* *}$ \\
PI-checking & $0.26^{* *}$ & $0.25^{* *}$ & $0.24^{* *}$ & $0.21^{* *}$ & $0.22^{* *}$ \\
PI-impulses & $0.21^{* *}$ & $0.20^{* *}$ & 0.14 & $0.23^{* *}$ & $0.17^{*}$ \\
PI-precision & 0.12 & 0.12 & 0.11 & 0.09 & 0.10 \\
PI-rumination & $0.35^{* *}$ & $0.29^{* *}$ & $0.29^{* *}$ & $0.24^{* *}$ & $0.31^{* *}$ \\
PI-washing & $0.16^{*}$ & $0.17^{*}$ & 0.13 & 0.19 & 0.12 \\
BDI & 0.15 & $0.17^{*}$ & $0.20^{*}$ & 0.08 & 0.09 \\
CEQ & 0.15 & $0.27^{* *}$ & $0.25^{*}$ & $0.20^{*}$ & 0.03 \\
\hline
\end{tabular}

${ }^{a}$ Note: TAF-scale=thought-action fusion scale, MOCI=Maudsley obsessive-compulsive inventory, PI=Padua inventory-revised, $\mathrm{BDI}=\mathrm{Beck}$ depression inventory, $\mathrm{CEQ}=$ creative experiences questionnaire. ${ }^{*} p<0.05 ;{ }^{* *} p<0.01$.

Table 3

Mean TAF-scores (and standard deviations) for students $(N=285$ ), normal controls $(N=20)$, OCD patients $(N=30)$, and patients with other anxiety disorders $(N=41)^{\mathrm{a}}$

\begin{tabular}{lcccc}
\hline & Students & Normal controls & OCD & $\begin{array}{c}\text { Other anxiety } \\
\text { disorders }\end{array}$ \\
\hline TAF-total & $20.39^{*}(10.53)$ & $20.24^{*}(11.41)$ & $30.69 \dagger(14.64)$ & $28.29 \dagger(13.07)$ \\
TAF-probability & $6.25^{*}(4.55)$ & $4.23^{*}(4.83)$ & $9.42 \dagger(6.88)$ & $8.54 \dagger(5.53)$ \\
$\quad$ probability self & $4.16^{*} \dagger(2.80)$ & $2.64^{*}(2.54)$ & $4.88 \dagger(3.01)$ & $4.94 \dagger(2.93)$ \\
$\quad$ probability others & $2.10^{*}(2.49)$ & $1.60^{*}(2.79)$ & $4.54 \dagger(4.95)$ & $3.60 \dagger(3.89)$ \\
TAF-morality & $14.21^{*}(8.06)$ & $15.90^{*} \dagger(9.36)$ & $21.27 \dagger(10.15)$ & $19.62 \dagger(9.62)$ \\
\hline
\end{tabular}

a Note: Scores not sharing the same superscript differed at the 0.05 level in one-way ANOVA (Tukey honestly significant differences).

one factor referring to probability and the other tapping morality bias. The probability factor can be divided into two related components, a probability self and probability others component. Second, internal consistency of all factors as well as the total TAF-scale proved to be satisfactory. Third, temporal stability of the TAF-scale was somewhat disappointing. Although within-subject TAF-scores over a 3-months interval correlated significantly, mean scores seemed to have dropped considerably. Apparently, then, TAF is unstable and susceptible to change. Perhaps, this instability is due to the fact that the data were collected in normal participants who had scores that predominantly fell in the left portion of the TAF distribution. Thus, it might well be the case that in a clinical sample, TAF-scores are highly stable, simply because the two types of biases indexed by the TAF-scale have a higher prevalence in such a sample. Clearly, the temporal stability of the TAF-scale in various clinical and non-clinical samples requires further research. 
Fourth, as to its association with widely used OCD measures (MOCI and PI-revised), it should be noted that TAF correlated with self-reports of obsessional problems. By and large, the association between TAF and obsessional symptoms remained significant when the contribution of depression levels and fantasy proneness was partialled out. It is important to note that the correlations found in this study pertained to a non-clinical sample. Given that Shafran et al. (1996) found different correlational patterns in students and obsessional participants, the possibility of generalising the current findings to obsessional populations may be limited. Finally, as expected, TAF-scores were higher for a clinical sample than for students and normal controls. However, OCD patients did not score significantly higher than patients suffering from other anxiety disorders. This casts some doubts on the idea that TAF is a highly specific feature of OCD. Rather, the current results support the view that TAF is a more pervasive bias that may occur in a variety of anxiety disorders. However, this does not rule out the possibility that TAF is more implicated in the development of OCD than it is in the aetiology of, say, panic disorder. In other words, TAF biases might be present in both OCD and panic disorder, but the causal status of these biases may be quite different in the two conditions. Obviously, this is an important issue for future studies.

Like Shafran et al. (1996), we found that compared to the normal sample, our clinical sample did not score higher on the morality subscale. Shafran et al. (1996) interpreted their failure to find a group difference with regard to the morality scale as indicating that this bias may be more common and less pathological than the probability bias. The current data support this interpretation, while, furthermore, the probability scale seemed to correlate more strongly with the various MOCI and PI-revised scales than did the morality scale. Also in line with Shafran et al. (1996), we found that scores on the probability self factor did not differ between students and OCD patients, while a significant difference was present with respect to the probability others factor. Shafran et al. (1996) explain this pattern of results by arguing that there is a rudimental rationality for the probability self construct, in that people might live up to their obsessive intrusion and, thus, actually suffer the foreseen consequences ("self-fulfilling prophecy"). For example, the intrusion "I will have a car accident" may be followed by reckless, or dangerously slow and careful driving, increasing the risk of actually being in an accident. The probability others factor, on the other hand, lacks such fundamental rational basis and may therefore be more exclusive to obsessional thinking.

Rachman (1997) noted that depression may affect the interpretation of intrusive thoughts in such a way that it leads to a pessimistic (TAF-like) explanation of intrusions. Indeed, we found a correlation between BDI and TAF-probability. On the other hand, additional analyses revealed that BDI-scores correlated with various MOCI and PI-revised scales (highest $r=0.46, p<0.01$ ), even after TAF-probability had been partialled out. This suggests that TAF biases do not represent the only link between depressive mood and obsessional problems.

The correlation between TAF-probability and the CEQ supports the idea that fantasy proneness may be implicated in several conditions. For example, earlier studies suggested that fantasy proneness might be an intermediate factor in the development of dissociation (Merckelbach, Muris, Horselenberg \& Stougie, 2000) and schizotypy (Allen \& Coyne, 1995). Clearly, the idea that thoughts have predictive value (as is implied in the probability bias) is a form of magical thinking that may have its roots in a general fantasy proneness trait. The precise linkage between obsessive intrusions, dissociation, schizotypy, fantasy proneness, and TAF is a fruitful area for further studies. 
In sum, the present results are in line with previous findings (Shafran et al., 1996) indicating that the TAF-scale is a reliable scale relevant to the measurement of obsessional cognitions. However, our data about the temporal consistency of the TAF-scale show that there is room for improvement. Also, the question of whether TAF-biases are exclusive features of OCD, or rather pathological biases in general, needs to be addressed in more depth.

\section{Acknowledgements}

The authors like to thank an anonymous reviewer for helpful comments on an earlier draft.

\section{References}

Allen, J. G., \& Coyne, L. (1995). Dissociation and vulnerability to psychotic experience: The Dissociative Experiences Scale and the MMPI-2. The Journal of Nervous and Mental Disease, 183, 615-622.

American Psychiatric Association (1994). Diagnostic and statistical manual of mental disorders. (4th ed.). Washington, DC: American Psychiatric Association.

Beck, A. T. (1967). Depression: Clinical, experimental, and theoretical aspects. New York: Harper \& Row.

Emmelkamp, P. M. G., \& Aardema, A. (1999). Metacognition, specific obsessive-compulsive beliefs and obsessivecompulsive behaviour. Clinical Psychology and Psychotherapy, 6, 139-145.

Hodgson, R. J., \& Rachman, S. (1977). Obsessional-compulsive complaints. Behaviour Research and Therapy, 15, 389-395.

Merckelbach, H., Muris, P., Horselenberg, R., \& Stougie, S. (2000). Dissociative experiences, response bias, and fantasy proneness in college students. Personality and Individual Differences, 28, 49-58.

Merckelbach, H., Muris, P., Schmidt, H., Rassin, E., \& Horselenberg, R. (1998). De Creatieve Ervaringen Vragenlijst als maat voor 'fantasy proneness' [The Creative Experiences Questionnaire as measure of 'fantasy proneness']. De Psycholoog, 33, 204-208.

Rachman, S. (1997). A cognitive theory of obsessions. Behaviour Research and Therapy, 35, 793-802.

Rachman, S. (1998). A cognitive theory of obsessions: Elaborations. Behaviour Research and Therapy, 36, 385-401.

Rachman, S., Shafran, R., Mitchell, D., Trant, J., \& Teachman, B. (1996). How to remain neutral: An experimental analysis of neutralization. Behaviour Research and Therapy, 34, 889-898.

Rachman, S., Thordarson, D. S., Shafran, R., \& Woody, S. R. (1995). Perceived responsibility: Structure and significance. Behaviour Research and Therapy, 33, 779-784.

Rassin, E., Merckelbach, H., Muris, P., \& Spaan, V. (1999). Thought-action fusion as a causal factor in the development of intrusions. Behaviour Research and Therapy, 37, 231-237.

Sanavio, E. (1988). Obsessions and compulsions: The Padua inventory. Behaviour Research and Therapy, 26, 169-177.

Shafran, R., Thordarson, M. A., \& Rachman, S. (1996). Thought-action fusion in obsessive compulsive disorder. Journal of Anxiety Disorders, 10, 379-391.

Van Oppen, P., Hoekstra, R. J., \& Emmelkamp, P. M. G. (1995). The structure of obsessive-compulsive symptoms. Behaviour Research and Therapy, 33, 15-23.

Wilson, S. C., \& Barber, T. X. (1978). The creative imagination scale as a measure of hypnotic responsiveness: Applications to experimental and clinical hypnosis. American Journal of Clinical Hypnosis, 20, 235-249. 